\title{
Lesions of Perirhinal and Parahippocampal Cortex That Spare the Amygdala and Hippocampal Formation Produce Severe Memory Impairment
}

\author{
Stuart Zola-Morgan,' Larry R. Squire, ' David G. Amaral, ${ }^{2}$ and Wendy A. Suzuki ${ }^{2,3}$ \\ 'Veterans Administration Medical Center, San Diego, California, 92161, and Department of Psychiatry, University of \\ California, San Diego, La Jolla, California 92093, ${ }^{2}$ The Salk Institute, San Diego, California 92138, and ${ }^{3}$ Group in \\ Neurosciences, University of California, San Diego, La Jolla, California 92093
}

In monkeys, bilateral damage to the medial temporal region produces severe memory impairment. This lesion, which includes the hippocampal formation, amygdala, and adjacent cortex, including the parahippocampal gyrus (the $\mathrm{H}^{+} \mathrm{A}+\mathrm{le}$ sion), appears to constitute an animal model of human medial temporal lobe amnesia. Reexamination of histological material from previously studied monkeys with $\mathrm{H}+\mathrm{A}+$ lesions indicated that the perirhinal cortex had also sustained significant damage. Furthermore, recent neuroanatomical studies show that the perirhinal cortex and the closely associated parahippocampal cortex provide the major source of cortical input to the hippocampal formation. Based on these 2 findings, we evaluated the severity of memory impairment in a group of monkeys that received bilateral lesions limited to the perirhinal cortex and parahippocampal gyrus (the PRPH lesion). The performance of the PRPH group was compared with that of monkeys with $\mathrm{H}^{+} \mathrm{A}^{+}$lesions, who had been studied previously, and with a group of normal monkeys. Monkeys with PRPH lesions were severely impaired on 3 amnesia-sensitive tasks: delayed nonmatching to sample, object retention, and 8-pair concurrent discrimination. On pattern discrimination, a task analogous to ones that amnesic patients perform well, monkeys in the PRPH group performed normally. Overall, monkeys with PRPH lesions were as impaired or more impaired than the comparison group of monkeys with $\mathrm{H}^{+} \mathrm{A}^{+}$lesions. These and other recent findings (Zola-Morgan et al., 1989b) suggest that the severe memory impairment in monkeys and humans associated with bilateral medial temporal lesions results from damage to the hippocampal formation and adjacent, anatomically related cortex, not from conjoint hippocampus-amygdala damage.

Bilateral damage to the hippocampal formation, amygdala, and adjacent cortex, including the parahippocampal gyrus (the $\mathrm{H}^{+} \mathrm{A}^{+}$ lesion), produces severe memory impairment in monkeys (Mishkin, 1982; Squire and Zola-Morgan, 1983; Mahut and

Received Mar. 8, 1989; revised June 9, 1989; accepted June 16, 1989.

This work was supported by the Medical Research Service of the Veterans Administration, NIH grants 19063, NS 16980, and MH 41479, the Office of Naval Research, and the McKnight Foundation. We thank Melodee Strukelj, Jasmine Allen, Michael Mesches, Amy Lockwood, and Melissa Hsu for behavioral testing, and Cecelia Leclair and Janet Weber for histological assistance.

Correspondence should be addressed to Stuart Zola-Morgan, Department of Psychiatry M-003, U.C.S.D. School of Medicine, La Jolla, CA 92093.

Copyright (C) 1989 Society for Neuroscience $0270-6474 / 89 / 124355-16 \$ 02.00 / 0$
Moss, 1984). (In this notation, $H$ refers to the hippocampus, $A$ to the amygdala, and the plus superscript $\left(^{+}\right)$to the cortical tissue adjacent to each structure.) This lesion appears to constitute an animal model of medial temporal lobe amnesia like that exhibited by the well-studied patient H.M. (Scoville and Milner, 1957).

The $\mathrm{H}^{+} \mathrm{A}^{+}$lesion produces greater memory impairment than a lesion limited to the hippocampal formation and parahippocampal cortex - the $\mathrm{H}^{+}$lesion (Mishkin, 1978; Mahut et al., 1982; Zola-Morgan and Squire, 1985, 1986; Zola-Morgan et al., 1989a). One possibility to explain these findings is that the more severe deficit occurs because the amygdala is damaged in the larger $\mathrm{H}^{+} \mathrm{A}^{+}$lesion but not in the more selective $\mathrm{H}^{+}$lesion (Mishkin, 1978; Murray and Mishkin, 1984, 1986; Saunders et al., 1984; Bachevalier et al., 1985). However, we recently found that stereotaxic bilateral lesions of the amygdala, which spared adjacent cortex, did not impair performance on 4 different memory tasks and did not exacerbate the memory impairment associated with hippocampal formation $\left(\mathrm{H}^{+}\right)$lesions alone (Zola-Morgan et al., 1989b).

A second possibility is that the $\mathrm{H}^{+} \mathrm{A}^{+}$lesion produces more severe memory impairment than the $\mathrm{H}^{+}$lesion because of damage to perirhinal cortex rather than because of damage to the amygdala. Reexamination of the histological material from one of the studies involving the $\mathrm{H}^{+} \mathrm{A}^{+}$lesion (Zola-Morgan et al., 1982 ) indicated that the perirhinal cortex sustained substantial damage (see the histological findings in Results). Furthermore, recent neuroanatomical studies show that the perirhinal cortex (areas 35 and 36) and the closely associated parahippocampal cortex (areas TH and TF) provide the major source of cortical input to the entorhinal cortex (Insausti et al., 1987). These 2 cortical regions thus provide the principal route by which information is exchanged between the neocortex and the hippocampal formation.

In the present study, we evaluated the severity of memory impairment in a group of monkeys that received conjoint bilateral lesions limited to the perirhinal cortex and the parahippocampal gyrus (the PRPH lesion). The performance of this group was compared with the performance of monkeys with the $\mathrm{H}^{+} \mathrm{A}^{+}$lesion that had been studied previously (Zola-Morgan et al., 1982; Zola-Morgan and Squire, 1984, 1985) and with a group of normal monkeys. Performance was tested on the delayed nonmatching to sample task, on 2 other tasks sensitive to human amnesia (delayed retention of object discriminations and 8-pair concurrent discrimination learning; Squire et al., 1988), 
and on a task analogous to ones that amnesic patients perform well (pattern-discrimination learning; Zola-Morgan and Squire, 1984).

\section{Materials and Methods}

\section{Subjects}

The findings from 14 cynomolgus monkeys (Macaca fascicularis) will be presented. All monkeys weighed between 3.0 and $4.8 \mathrm{~kg}$ at the beginning of behavioral testing and were estimated to be 3-5 ycars old, i.e., young adults (Hartley et al., 1984; Szabo and Cowan, 1984).

The 14 monkeys belonged to 3 experimental groups. Four male monkeys received bilateral lesions of the PRPH. The intent was to spare the amygdaloid complex and the hippocampal formation (dentate gyrus, hippocampus proper, subicular complex, and entorhinal cortex). The 4 monkeys in the $\mathrm{H}^{+} \mathrm{A}^{+}$group ( 2 males, 2 females) received bilateral lesions with the intent to remove the amygdala and all subdivisions of the hippocampal formation, as well as much of the parahippocampal cortex. Behavioral data for this group have been presented as part of 3 previous reports (Zola-Morgan et al., 1982; Zola-Morgan and Squire, $1984,1985)$ and are included here for purposes of comparison. Finally, 6 monkeys ( 5 males, 1 female) were unoperated and comprised a normal control group (N). Three of these monkeys (N4, N5, N6) were tested at the same time as the monkeys in the PRPH group. The other 3 normal monkeys (N1, N2, N3) were tested at the same time as the $\mathrm{H}^{+} \mathrm{A}^{+}$group. Behavioral data for $\mathrm{N} 1, \mathrm{~N} 2$, and $\mathrm{N} 3$ have also been reported previously (Zola-Morgan and Squire, 1984, 1985; Zola-Morgan et al., 1989a, b).

\section{Surgery}

PRPH group. At the time of surgery, animals were preanesthetized with ketamine hydrochloride $(12-15 \mathrm{mg} / \mathrm{kg}, \mathrm{i.m}$.) and then brought to a surgical plane of anesthesia with intravenous administration of Nembutal $(25-30 \mathrm{mg} / \mathrm{kg})$. Heart rate and body temperature were monitored continuously, and additional anesthetic was administered when necessary.

The monkey's head was positioned in a specially designed headholder that permitted unobstructed access to the temporal portion of the skull. The temporal muscles on each side were fully retracted, the zygomatic arch was removed, and openings were made on each side of the skull to expose much of the anterior and ventrolateral portions of the temporal lobe. Mannitol solution ( $2 \mathrm{~g} / \mathrm{kg}$, i.v.) was administered to reduce brain volume and allow better visualization of the ventromedial surface of the brain.

For the PRPH lesions, the intent was to remove approximately 3-4 $\mathrm{mm}$ of cortex lateral to the full rostrocaudal extent of the rhinal sulcus. The ablation was then expanded caudally (at a level approximately 2 $\mathrm{mm}$ caudal to the limit of the rhinal sulcus) so as to encompass the TH and TF fields of the parahippocampal cortex (removing approximately $10 \mathrm{~mm}^{2}$ ). The lateral border for this portion of the lesion was the occipitotemporal sulcus. Because the distance between the rhinal and occipitotemporal sulci was highly variable, we standardized the lesions by continuing caudally from the rhinal sulcus for a distance of approximately $10 \mathrm{~mm}$ in each case (Fig. 2, top panel).

The pial surface over the intended lesion was first cauterized, and the tissue was then removed by suction using a glass pipette with an angled tip. Cortical tissue removal continued slowly until the white matter was approached. At a level below the rostral tip of the lateral ventricle, we attempted to sever the white matter located deep and just lateral to the fundus of the rhinal sulcus for a rostrocaudal distance of about $2 \mathrm{~mm}$. The objective was to damage projections from cortical regions other than the perirhinal and parahippocampal cortices that traverse this area en route to the hippocampal formation.

$\mathrm{H}^{+} \mathrm{A}^{+}$group. The surgical preparation for this group has been described in detail previously (Zola-Morgan and Squire, 1984, 1985). For the amygdala lesion, the frontotemporal junction was elevated, and all gray matter anterior to the rostralmost portion of the hippocampus and medial to the white matter of the temporal lobe was aspirated with a small-gauge sucker. The hippocampus was approached by elevating the occipitotemporal convexity, and the hippocampal formation, including the entorhinal cortex, and much of the parahippocampal cortex were then removed.

\section{Behavioral testing}

Monkeys were allowed 6-8 weeks of recovery prior to the start of behavioral testing. Pretraining and formal testing were carried out in a
Wisconsin General Test Apparatus (Harlow and Bromer, 1938). Four different tasks-i.e., trial-unique delayed nonmatching to sample, pattern discrimination, delayed retention of object discriminations, and concurrent discrimination learning - were administered to all monkeys in the order listed under Behavioral findings. These tasks are described in detail in Zola-Morgan et al. (1989a).

\section{Retrograde tracer studies}

In order to determine the extent to which the intended PRPH lesion had deafferented the hippocampal formation (particularly the entorhinal cortex) from its cortical inputs, in 2 of the 4 PRPH animals the entorhinal cortex was injected with a retrograde tracer. The contralateral amygdala was injected with a second retrograde tracer to insure that significant loss of corticoamygdaloid connections had not occurred due to inadvertent damage to fibers traveling within or close to the lesioned area. Following surgical procedures similar to those described above, animals PRPH1 and PRPH3 were placed in a Kopf stereotaxic apparatus. Using coordinates derived from the atlas of Szabo and Cowan (1984) and guided by electrophysiological recording along the trajectory of the intended injection site, injections of retrograde tracers were placed in the entorhinal cortex of one side and in the amygdaloid complex on the other side. In PRPH1, $500 \mathrm{nl}$ of $2.0 \%$ Diamidino yellow (DY) was placed into the entorhinal cortex on the left side, and $500 \mathrm{nl}$ of $3.0 \%$. Fast blue (FB) was aimed at the lateral nucleus of the amygdala on the right side. The animal was allowed to survive 2 weeks after the injections. In PRPH3, the amygdaloid injection was similar (though on the left side), but the entorhinal injection on the right side consisted of 100 $\mathrm{nl}$ of a $2 \%$ solution of WGA-HRP. The survival time after the DY injection was $14 \mathrm{~d}$ and, after the WGA-HRP injection, $2 \mathrm{~d}$ (the 2 tracers were placed in separate surgeries to accommodate the different survival times).

\section{Histological processing}

The animals were killed by transcardial perfusion of fixatives. Following deep anesthetization and loss of the corneal reflex, the animals were perfused first with a solution of $1 \%$ paraformaldehyde in $0.1 \mathrm{M}$ phosphate buffer followed by $4 \%$ paraformaldehyde in the same buffer. The brains were cryoprotected in glycerol solutions and sectioned in the coronal plane at $50 \mu \mathrm{m}$ on a freezing microtome. Every fifth section was mounted and stained with thionin to assess the extent of the lesions. In the animals injected with retrograde tracers, a second series of sections was mounted, and the distribution of retrogradely labeled cells was analyzed with a Leitz Dialux 20 microscope and fluorescence illumination. The distribution of labeled cells was plotted using a computer-aided digitizing system. In case PRPH3, a third series of sections was prepared using standard procedures for the demonstration of WGA-HRP in retrogradely labeled cells (Insausti et al., 1987).

\section{Results}

\section{Histological findings}

\section{Lesions of the PRPH}

General observations. The location of the perirhinal and parahippocampal regions is illustrated in Figure 1, which shows line drawings of representative coronal sections through the temporal lobe of $M$. fascicularis. These areas are also indicated on the ventral surface of a control brain in Figure 2. A detailed cytoarchitectonic description of these regions is available in Amaral et al. (1987) and Insausti et al. (1987).

While the extents of the ablations were quite similar in the 4 PRPH animals, there was some variability in the amount of tissue removed. Animals PRPH2-4 had very similar lesions, and animal PRPH1 had a somewhat smaller lesion. Figure 2 illustrates the ventral brain surface from each of the experimental cases, together with the location of the intended lesion. The extents of the lesions in each case are also plotted on representative coronal sections (Fig. 3) redrawn from the atlas of Szabo and Cowan (1984). These plots were constructed by matching sections from each case with the standard plates in the atlas and indicating the extent of the lesion at that level. 


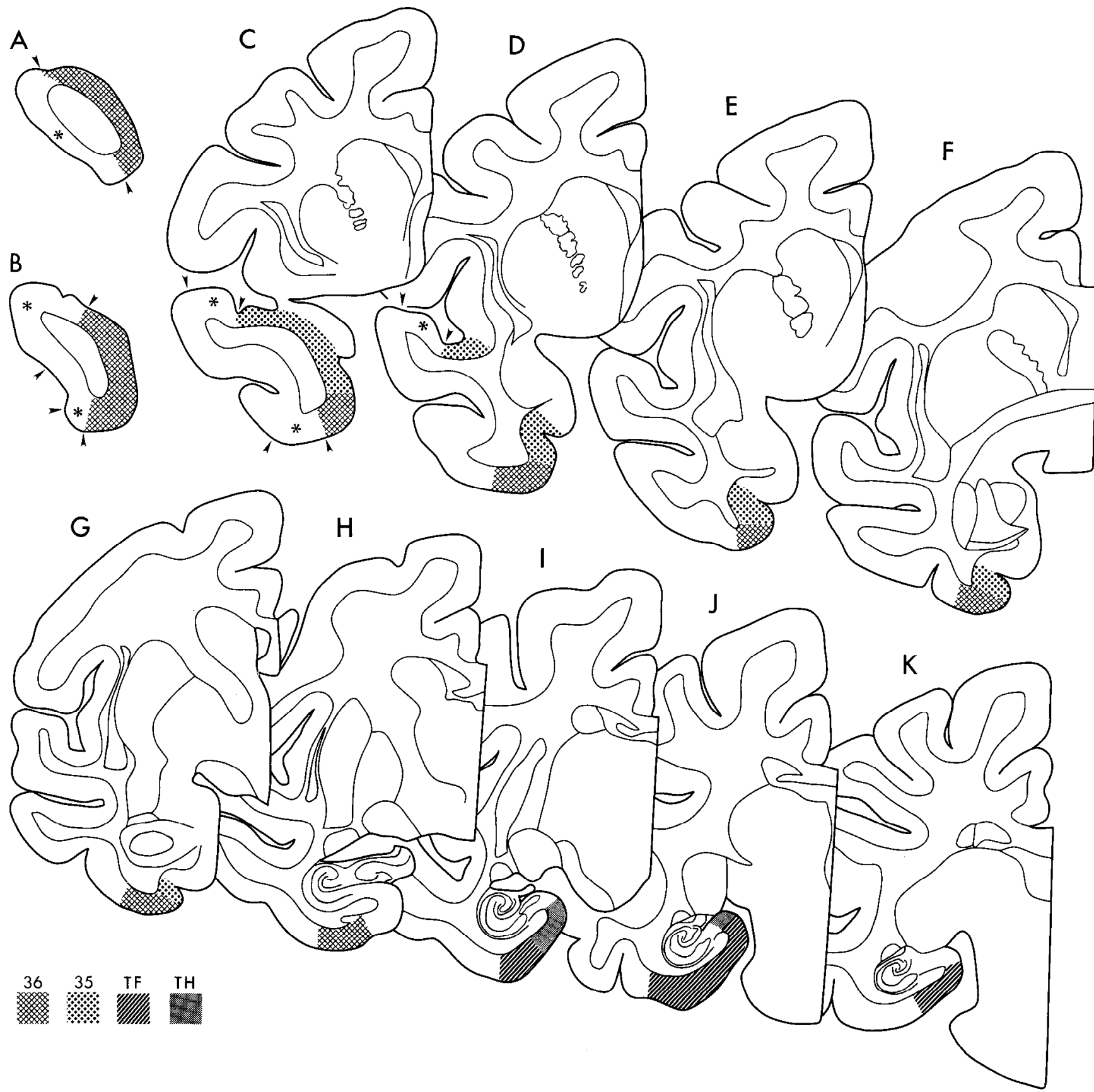

Figure 1. Drawings of representative coronal sections through the temporal lobe of Macaca fascicularis arranged from rostral $(A)$ to caudal $(K)$. Areas 35 and 36 of the perirhinal cortex and areas TF and TH of the parahippocampal cortex are indicated with distinct shading patterns (key at bottom left). The lesion in the present study was intended to remove all of the shaded regions. The lateral portion of the temporal polar cortex (indicated by asterisks and bounded by arrowheads) shares cytoarchitectonic similarities with area 36 and was labeled area $36 \mathrm{pl}$ by Insausti et al. (1987). This area was not part of the intended lesion.

The PRPH lesions were generally smaller than intended. The most anterior portion of the perirhinal cortex (the temporal polar portion) was largely spared in all cases. However, the more ventral portion of the perirhinal cortex that lines the rhinal sulcus under the amygdala and adjacent to the entorhinal cortex was nearly completely removed in all cases. While the lateral aspect of the parahippocampal cortex was extensively damaged in all cases, the ablation did not extend as far medially as intended and area TH was directly damaged in only one case.

The full rostrocaudal extent of the ablation in animal PRPH3 is shown in a series of photomicrographs in Figure 4. This animal had the lesion that most closely approximated the in- tended lesion. Accordingly, we begin by describing the ablation in this animal. We then provide a shorter, comparative description of the lesions in the other animals.

$P R P H 3$. The lesion in animal PRPH3 began close to the anterior pole of the temporal lobe at a level anterior to the amygdala. At this level (A22.0), the piriform and periamygdaloid cortices form a prominent bulge on the medial surface of the temporal lobe (Fig. 3). The lesion appeared at this level as a small defect confined to the superficial layers of ventral area 35 . At the rostral pole of the amygdala (A19.0), the lesion expanded on both sides to encompass all layers of area 35 and extended laterally into area 36 . On the left side, but not on the 

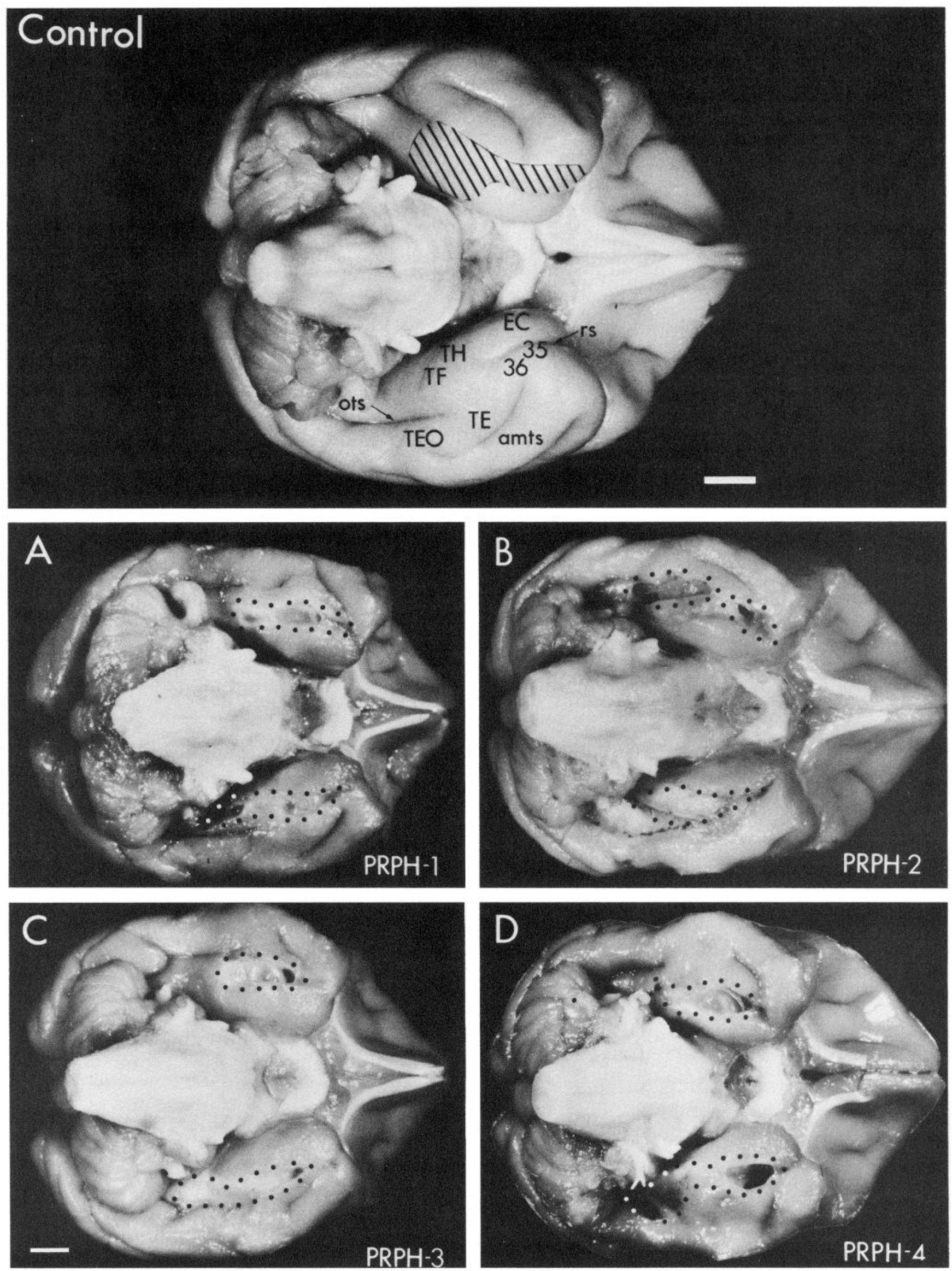
right, the rhinal sulcus had been broached, and there was slight damage to the most lateral part of the anterior pole of the entorhinal cortex. Continuing caudally, the lesion expanded both mediolaterally and dorsoventrally. At a level through the caudal third of the amygdala (A16.4), the lesion on the left side extended into the white matter just below the lateral nucleus of the amygdala, but the amygdala was not directly involved. At this level, the lesion extended laterally from the fundus of the rhinal sulcus approximately $4 \mathrm{~mm}$ to the opening of the anterior middle temporal sulcus. The perirhinal cortex was entirely eliminated, and the lesion slightly involved the most lateral portion of the entorhinal cortex. The lesion on the right side also entered the white matter deep to the lateral nucleus of the amygdala, and, for a short rostrocaudal distance, the lesion extended for approximately $200 \mu \mathrm{m}$ into the lateral nucleus. The right lesion was narrower mediolaterally, and the rhinal sulcus and entorhinal cortex were intact.

Through the level of the rostral pole of the hippocampus (A15.5), the lesion continued through the white matter deep and lateral to the fundus of the rhinal sulcus and entered the ventricle on both sides. The mediolateral extent of the lesion at this level was approximately $4 \mathrm{~mm}$. The lesion continued caudally in the same mediolateral position and maintained the same size along the full rostrocaudal extent of the entorhinal cortex. Much of the white matter subjacent to the perirhinal cortex was removed. There appeared to be minor punctate damage to the alveus of the hippocampus on the right side (Fig. $4 E$ ), with some minor CA1 cell loss. At caudal levels of the entorhinal cortex on the right side, the ablation slightly involved the lateral aspect of the entorhinal cortex. The fields of the hippocampal formation on the left side were intact except for some punctate CA1 cell loss at the caudal pole of the hippocampus. On the right side, the lesion continued caudally into the parahippocampal cortex and encompassed the lateral two-thirds of area TF. The medial third of area TF and area TH were not involved by the lesion. The laterally situated area TE was spared as well. The lesion ended rostral to the caudal pole of the hippocampus at a level near the transition of area TF to area OA. On the left side, the lesion directly involved about the same amount of area TF as on the right side; area TH was similarly spared, but unlike on the right side, where there appeared to be little if any extraneous damage to areas TE or OA, there appeared to have been an infarct on the left side that damaged these fields. Thus, at level A3.6, where the lesion had already ended on the right side, the lesion on the left side expanded lateral to the occipital temporal sulcus and into area TEO. The lesion then narrowed mediolaterally and extended caudally for an additional $3 \mathrm{~mm}$. The lesion ended just as area 17 was appearing in the calcarine sulcus.

To summarize, the lesion in PRPH3 bilaterally removed all of the perirhinal cortex beginnning just rostral to the rostral pole of the amygdala. The lesion also transected the white matter that lies subjacent to the perirhinal cortex for much of the rostrocaudal extent of the entorhinal cortex. Approximately the lateral two-thirds of area TF was removed bilaterally. On both sides, neither the medial third of area TF nor area TH was damaged. The right lesion did little or no extraneous damage to area TE and ended at the transition of area TF to OA. On the left side, an infarct damaged area TEO and a small portion of rostral OA.

$P R P H 2$. The lesion in animal PRPH2 was quite similar to that just described but was somewhat larger mediolaterally at all levels. It started at the rostral pole of the amygdala slightly caudal to the level of the lesion in PRPH3. The lesion quickly expanded to encompass the full mediolateral and dorsoventral extents of the perirhinal cortex. The white matter subjacent to the perirhinal cortex was removed along its full extent, and the lesion extended into the ventricle at the rostral pole of the hippocampus. The lesion involved the rhinal sulcus on both sides, and the lateral aspect of the entorhinal cortex was directly damaged. Compared with PRPH3, the lesion in PRPH2 extended somewhat more laterally toward the anterior middle temporal sulcus. Some small portion of area TE may have been damaged bilaterally. Caudal to the entorhinal cortex, the lesion expanded mediolaterally and removed nearly all of area TF bilaterally. Area TH, however, was not involved in the lesion. Continuing caudally, the lesion extended slightly lateral to the occipitotemporal sulcus on both sides and thus likely directly damaged a small portion of area TEO. The lesion continued for approximately $1 \mathrm{~mm}$ caudal to the pole of the hippocampus and slightly involved field OA. As in PRPH3, there were small patches of CAl cell loss on both sides that were likely due to direct damage to fibers in the alveus.

PRPH4. The lesion in PRPH4 was similar to those just described and was substantially larger on the left side than on the right. The same amount of perirhinal cortex was removed in this case as in the previous cases, and the white matter subjacent to the perirhinal cortex was also as extensively damaged. Caudally, the lesion extended more medially in the parahippocampal cortex and directly involved area TH. Area TF was more extensively damaged in this case than in the previous cases. On the right side, the lesion was more limited mediolaterally and appeared not to impinge on areas TE or TEO. It ended just behind the caudal pole of the hippocampus and involved a small amount of area OA. On the left side, the lesion extended considerably lateral to the occipitotemporal sulcus, apparently due to a fairly large infarct of the left inferior temporal gyrus. This damage was most extensive at a level close to the caudal pole of the hippocampus and heavily involved area TEO. It should be noted that all the ventricles were markedly enlarged in this animal.

PRPH1. The smallest lesion was observed in PRPH1. The lesion in this animal began more caudally (at approximately the midpoint of the amygdala) and was less extensive mediolaterally than in the previous cases. For much of its rostrocaudal extent, at least some of the more laterally situated area 36 was left intact bilaterally. Moreover, the white matter subjacent to the rhinal sulcus was mainly intact up to the caudal pole of the entorhinal cortex. At this level, the lesion extended into the ventricle bilaterally and transected the white matter. The lesion continued caudally in the lateral half of area TF and ended bilaterally at

Figure 2. Photographs of the ventral surface of the monkey brain. Top panel, Normal control brain with the extent of the intended lesion shown by hatching. The major cortical regions and sulci are also indicated. $A-D$, Ventral surfaces of the 4 experimental animals. The lesions have been outlined with dots. Abbreviations: amts, anteromedial temporal sulcus; $E C$, entorhinal cortex; ots, occipitotemporal sulcus; $T F$, $T H$, parahippocampal cortex; $r s$, rhinal sulcus; 35,36 , perirhinal cortex. Scale bar, $5 \mathrm{~mm}$. 


\section{PRPH 1}

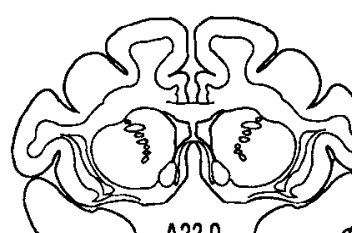

00 A22.0
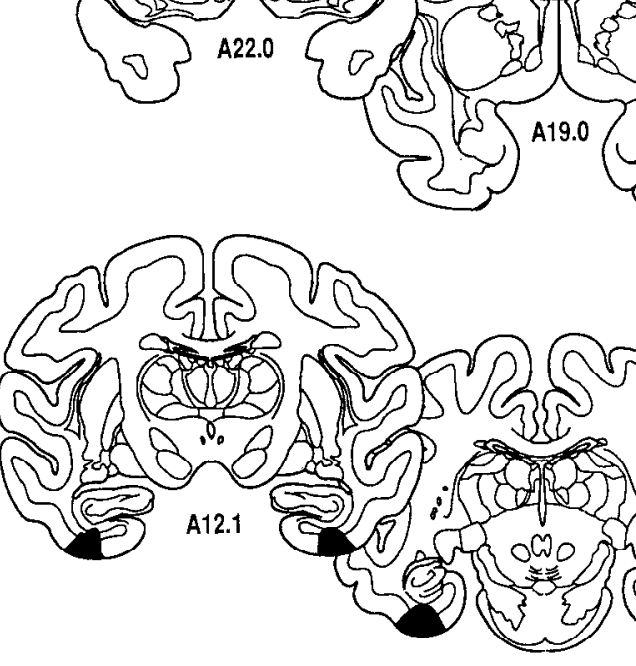

A7.6

PRPH 2
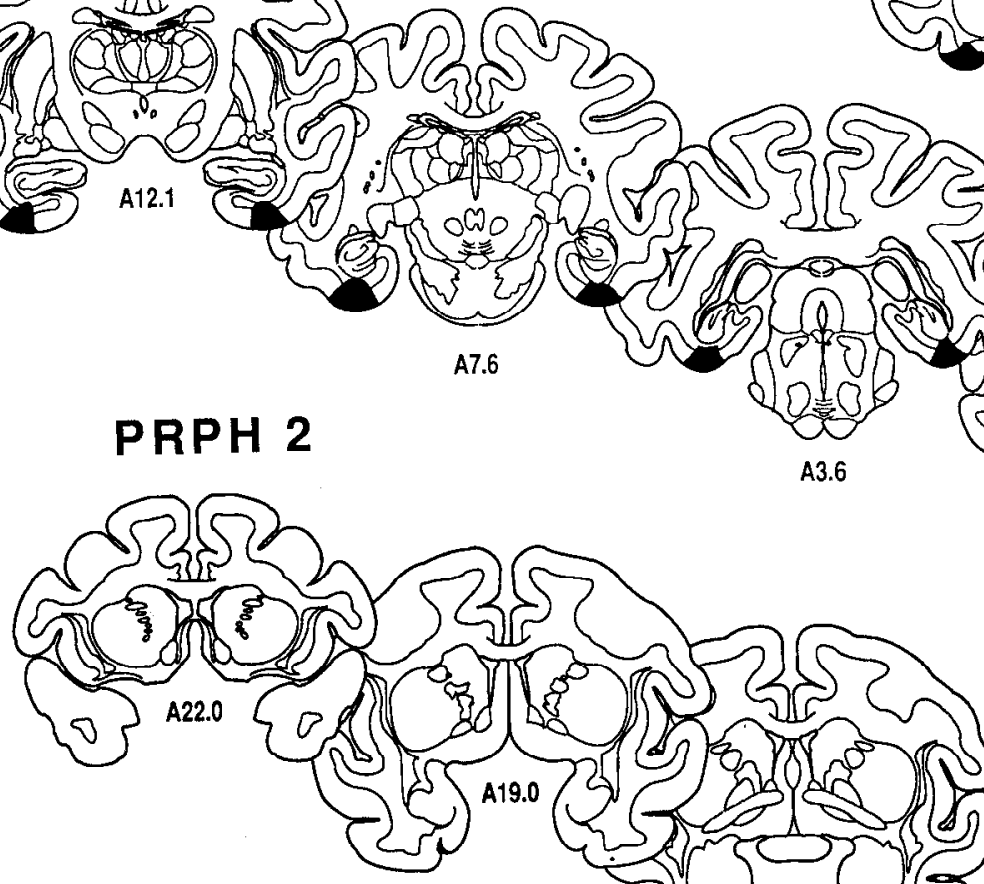

A3.6
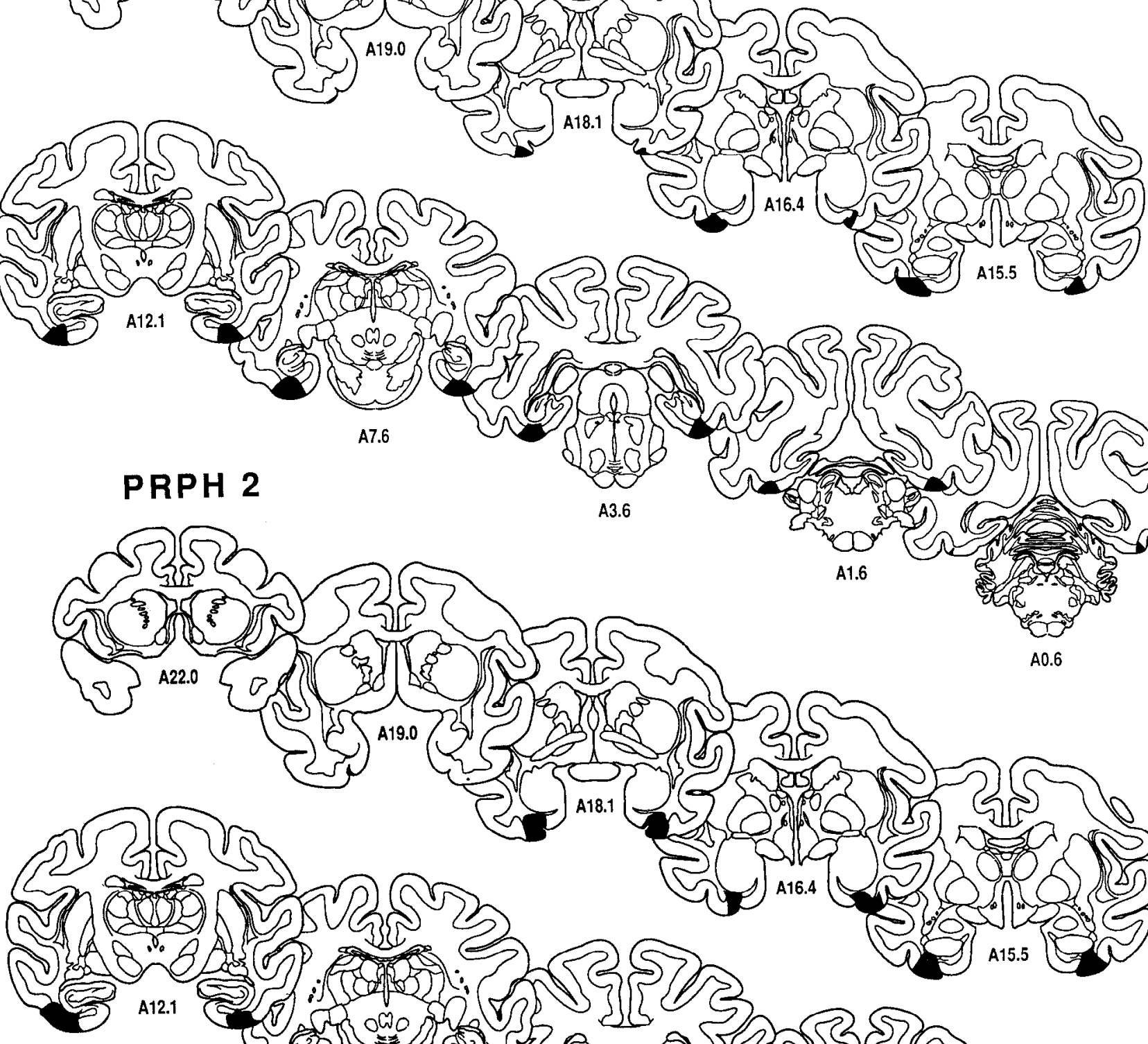


\section{PRPH 3}
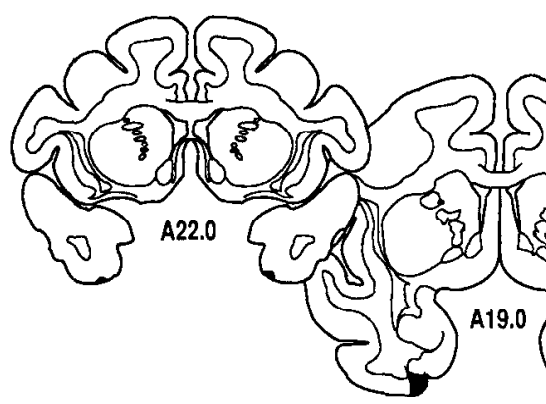

230

M (1)

(2)

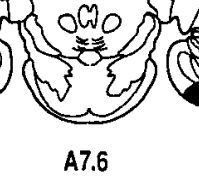

\section{PRPH 4}
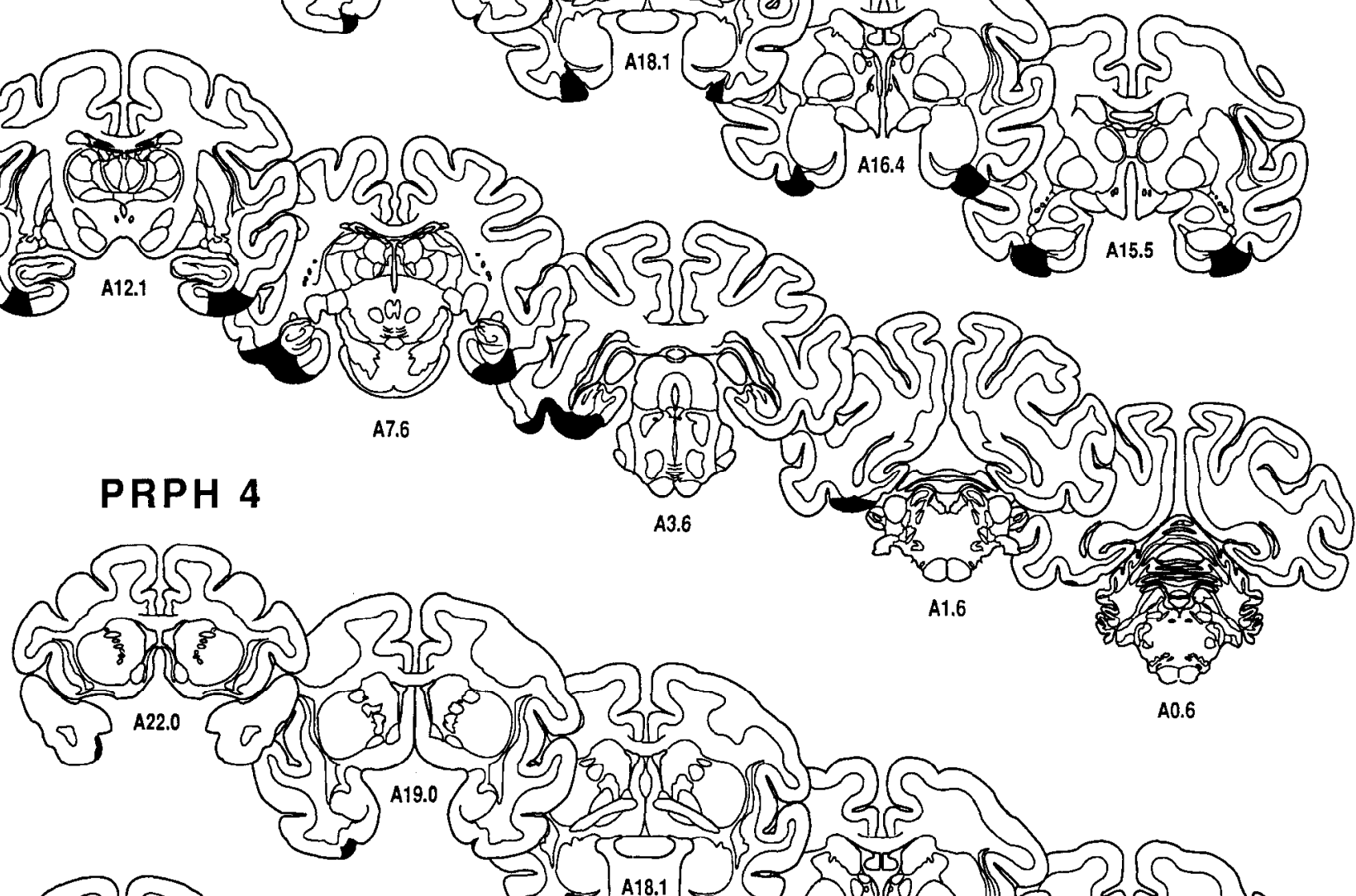

20.5.

(1) -

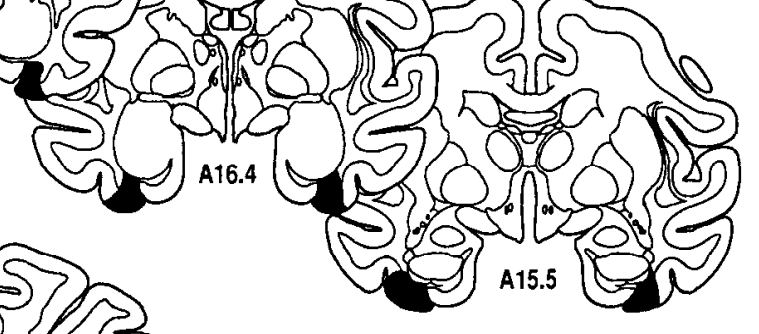

A12.1 (2) दे

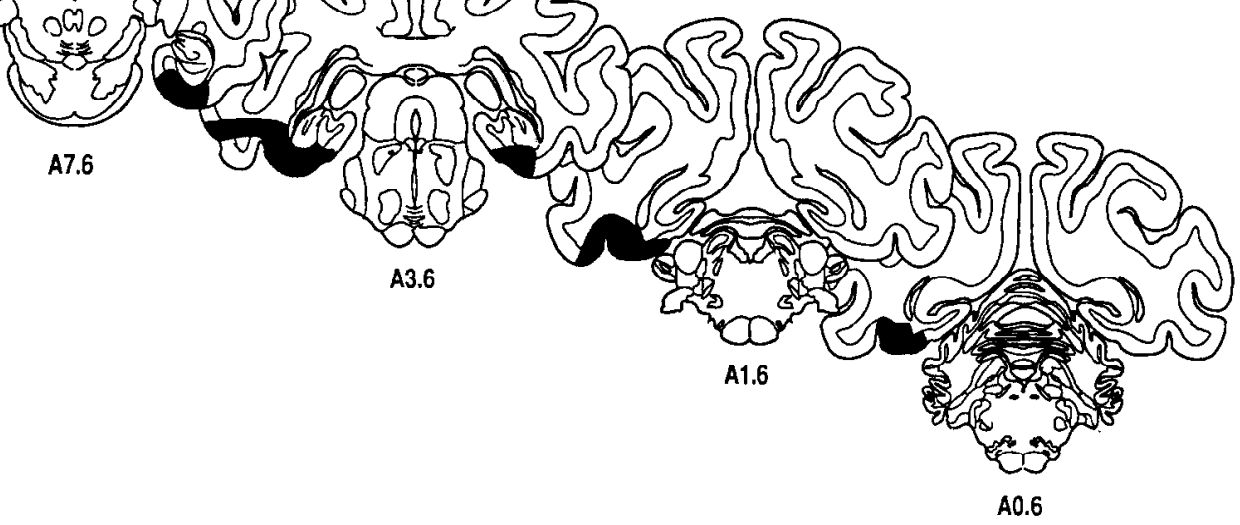


the caudal pole of the hippocampus. As in animals PRPH2 and PRPH3, there were patches of punctate cell loss in the CA1 field of the hippocampus bilaterally, though there was little or no direct damage to the entorhinal cortex.

\section{Summary of histological findings}

Lesions of the PRPH. The lesions were somewhat smaller than intended. In cases PRPH2, PRPH3, and PRPH4, the ventrally situated perirhinal cortex was completely eliminated. Moreover, the white matter subjacent to the perirhinal cortex was extensively damaged in these 3 cases. It is likely, therefore, that many of the fibers directed to the entorhinal cortex from cortical regions other than the perirhinal and parahippocampal cortex were eliminated (see below). At least the lateral half of area TF was removed in these 3 cases; area TH was directly damaged only in case PRPH4. Extraneous damage to the laterally adjacent areas TE and TEO, the hippocampal formation, and the amygdala was not extensive and generally not bilaterally symmetrical. The smallest lesion was observed in PRPH1. The damage in this animal differed from the other lesions in that there was substantial preservation of the lateral portions of area 36. Also, the white matter deep to the perirhinal cortex was transected for only a short distance at a level near the caudal pole of the entorhinal cortex.

Combined lesions of the hippocampus and the amygdala $\left(\mathrm{H}^{+} \mathrm{A}^{+}\right)$. Previous histological descriptions of this group of 4 animals focused primarily on the extent of damage to the hippocampal formation and the amygdaloid complex (Zola-Morgan et al., 1982; Zola-Morgan and Squire, 1984, 1985). Removal of these 2 structures was nearly complete in all 4 animals. We have now reexamined the histological material from these monkeys in order to assess the extent of damage to the perirhinal and parahippocampal cortices. It is clear that in each case there was significant bilateral damage to the perirhinal cortex. However, unlike the lesions in the PRPH animals, the $\mathrm{H}^{+} \mathrm{A}^{+}$lesions in all cases left some laterally situated portions of area 36 intact. Conversely, the $\mathrm{H}^{+} \mathrm{A}^{+}$animals had a substantially greater removal of the parahippocampal cortex than did the PRPH animals. Essentially all of areas TF and TH were removed in the $\mathrm{H}^{+} \mathrm{A}^{+}$cases. Caudal portions of areas TE and TEO appeared to be damaged substantially in the $\mathrm{H}^{+} \mathrm{A}^{+}$animals but not in the PRPH animals. In addition, at least some of the white matter located lateral to the amygdaloid complex was damaged bilaterally in all the $\mathrm{H}^{+} \mathrm{A}^{+}$animals, and some minor damage was also observed in the lateral aspect of the substantia innominata. In summary, this $\mathrm{H}^{+} \mathrm{A}^{+}$group had sustained more damage to structures surrounding the amygdala than was previously appreciated.

\section{Description of retrograde tracer studies}

Animals PRPH1 and PRPH3 received injections of different retrograde tracers in the entorhinal cortex on one side and in the contralateral amygdaloid complex. The lesion placed in animal PRPH1 was substantially smaller than in the other experimental animals and produced only a moderate behavioral impairment. Therefore, we will describe only the results of the retrograde tracing studies for animal PRPH3.

The injection of the entorhinal cortex was on the right side in animal PRPH3 and was located in the medial aspect of the caudal entorhinal cortex. The injection of the amygdala was on the left side and was located in the ventromedial aspect of the lateral nucleus. This injection also involved the lateral aspect of the parvicellular division of the basal nucleus (Fig. 4C). The distribution of the retrogradely labeled cells resulting from the entorhinal cortex injection will be described first (Fig. 5, right). In general, there were far fewer labeled cells in the neocortex than would be expected from a similarly placed injection in an unoperated animal (Insausti et al., 1987). There were no labeled cells in the frontal cortex, for example, whereas there are usually numerous labeled cells in the caudal portions of the orbitofrontal and medial frontal cortices. Similarly, there were only 2 labeled cells in the anterior cingulate cortex, a region that normally projects heavily to the entorhinal cortex (Insausti et al., 1987). In the temporal lobe, many retrogradely labeled cells were observed in the anterior portion of the remaining perirhinal cortex. However, at more caudal levels of the temporal lobe, i.e., at levels through the extent of the lesion, no retrogradely labeled cells were observed in the region immediately lateral to the lesion. Thus, if there were remnants of the perirhinal or parahippocampal regions located lateral to the lesion, they no longer maintained patent connections with the entorhinal cortex. A few labeled cells were observed in the agranular insula cortex and along the convexity of the superior temporal gyrus. In the retrosplenial cortex, labeled cells were observed in approximately the same high density as in an unoperated animal. No labeled cells were observed in the dorsal bank of the superior temporal sulcus where numerous labeled cells are generally seen in nonlesioned animals (Insausti et al., 1987). Within the hippocampal formation, there was heavy retrograde labeling of the deep layers of the entorhinal cortex and the presubiculum and fewer labeled cells in the hippocampus and subiculum. There were also numerous labeled cells in areas TF and TH located medial to the ablations. In contrast to the paucity of retrogradely labeled cells in the neocortex, there were large numbers of labeled cells located subcortically. In particular, there were large numbers of retrogradely labeled cells in the claustrum, the lateral and accessory basal nuclei of the amygdaloid complex, the medial septum and nucleus of the diagonal band, the rostral intralaminar nuclei, and the supramammillary region.

In contrast to the limited cortical labeling seen on the side of the entorhinal injection, the injection of retrograde tracer into the amygdaloid complex appeared to result in a relatively normal distribution of labeled cells in diverse regions of the neocortex. As illustrated in Figure 5 (left), numerous labeled cells were observed in areas $12,13 \mathrm{~A}$, and 14 of the orbitofrontal cortex and in areas 32,25 , and 24 of the medial frontal and cingulate cortices. In the temporal lobe, heavy labeling was observed in the medial and lateral parts of the rostral perirhinal cortex (areas 36pm and 36pl of Insausti et al., 1987), in the dorsal bank of the superior temporal gyrus, and in area TE, mainly in the ventral bank of the superior temporal sulcus. Labeled cells were also located ventromedially in area TE; at least some of which were situated immediately lateral to the lesion. Many cells were also observed in the insula cortex, mainly in its agranular division. There were also many labeled cells located in the deep layers of the entorhinal cortex and in the pyramidal cell layer of field CA1 near its border with the subiculum. As in the case of the entorhinal injection, there were numerous retrogradely labeled cells in several subcortical regions. Their distribution was similar to that reported previously (Aggleton et al., 1980; Mehler, 1980; Norita and Kawamura, 1980).

To summarize, in addition to eliminating the major cortical afferents to the entorhinal cortex that arise from the perirhinal and parahippocampal cortices, the PRPH lesion also appears 
to have eliminated most of the neocortical afferents originating in the orbitofrontal cortex, the cingulate cortex, and the superior temporal gyrus (Insausti et al., 1987). In contrast, essentially all of the cortical afferents to the amygdala, except for those arising from the perirhinal and parahippocampal cortices themselves, appear to have been left largely intact. Even connections arising from cells situated in area $\mathrm{TE}$, just lateral to the lesion, were not compromised.

\section{Behavioral findings}

Delayed nonmatching to sample. Three of the 4 monkeys in the PRPH group were unable to reach criterion level performance on the basic task within 1000 trials of testing (these 3 monkeys averaged $59 \%$ correct during trials $900-1000$; the fourth monkey, PRPH l, who had the smallest lesion, was able to reach criterion level in 580 trials). At this point, the testing procedure was modified so that the sample stimulus was presented twice in succesion, instead of only once (Aggleton and Mishkin, 1983). Only 1 of the 2 sample presentations was rewarded, and the order of reward was determined randomly for each trial. With the benefit of double sample presentation, 2 of the 3 PRPH monkeys (PRPH2, PRPH3) were able to reach learning criterion (after 1100 trials and 1680 trials, respectively). The remaining monkey (PRPH4) was performing at only $56 \%$ correct when testing was discontinued after 2000 trials.

Compared with the normal group, both operated groups were impaired in their ability to learn the basic task (Fig. $6 \mathrm{~A}$, Table 1; mean trials to reach learning criterion: $\mathrm{N}=143, \mathrm{H}^{+} \mathrm{A}^{+}=790$, PRPH $=1340 ; p$ 's $<0.05$; the statistical findings were the same when animal PRPH4 was excluded). Three of the 4 PRPH monkeys required more trials than any of the $4 \mathrm{H}^{+} \mathrm{A}^{+}$monkeys to learn the basic task, but the comparison was not significant ( $p$ $>0.10$ ).

Figure $6 B$ shows performance as the delay was increased from $8 \mathrm{sec}$ to $10 \mathrm{~min}$, and Tables 1 and 2 show individual scores (monkey PRPH4 was not tested on the delays). An analysis of variance involving all 3 groups and 3 delays ( 15 and $60 \mathrm{sec}$, and $10 \mathrm{~min})$ revealed a significant effect of group $(F[2,10]=29.7$, $p<0.001)$, delay $(F[2,20]=23.1, p<0.001)$, and no significant group $\times$ delay interaction $(F[4,20]=0.1, p>0.1)$. Separate comparisons based on each group's scores averaged across the same 3 delays ( 15 and $60 \mathrm{sec}$, and $10 \mathrm{~min}$ ) revealed that both the $\mathrm{H}^{+} \mathrm{A}^{+}$and $\mathrm{PRPH}$ groups were significantly impaired relative to the normal group $(t$ 's $>3.8, p$ 's $<0.01)$. The $\mathrm{H}^{+} \mathrm{A}^{+}$group scored lower than the PRPH group $\left[\mathrm{H}^{+} \mathrm{A}^{+}=61 \%, \mathrm{PRPH}=\right.$ $72 \%, t(5)=2.1, p<0.05]$.

The performance scores for the PRPH group, however, underestimate the severity of impairment, because 2 of the 3 PRPH monkeys required double sample presentation. Indeed, upon completion of testing at each of the first 3 delays, these 2 monkeys (PRPH2, PRPH3) were given 10-20 additional trials using the standard procedure of presenting the sample object only once. The average scores for these 2 monkeys using the doublepresentation procedure were 92,77 , and $71 \%$ at delays of $8 \mathrm{sec}$, $15 \mathrm{sec}$, and $60 \mathrm{sec}$, respectively. The corresponding scores using the single-presentation procedure were 70,60 , and $55 \%$. By

\begin{tabular}{|c|c|c|c|c|c|}
\hline \multirow[b]{2}{*}{ Group } & \multirow{2}{*}{$\begin{array}{l}\text { Trials to } \\
\text { criterion }\end{array}$} & \multicolumn{4}{|c|}{ Delays } \\
\hline & & $8 \mathrm{sec}$ & $15 \mathrm{sec}$ & $60 \mathrm{sec}$ & $10 \mathrm{~min}$ \\
\hline \multicolumn{6}{|l|}{ Normal } \\
\hline 1 & 120 & 91 & 98 & 91 & 82 \\
\hline 2 & 180 & 92 & 92 & 90 & 85 \\
\hline 3 & 140 & 90 & 86 & 83 & 74 \\
\hline 4 & 180 & 90 & 95 & 85 & 80 \\
\hline 5 & 160 & 90 & 96 & 97 & 80 \\
\hline 6 & 80 & 90 & 92 & 89 & 92 \\
\hline Mean & 143 & 91 & 93 & 89 & 82 \\
\hline \multicolumn{6}{|l|}{$\mathbf{H}^{+} \mathbf{A}^{+}$} \\
\hline I & 1000 & 90 & 71 & 62 & 54 \\
\hline 2 & 740 & 91 & 64 & 68 & 44 \\
\hline 3 & 800 & 90 & 65 & 58 & 51 \\
\hline 4 & 620 & 91 & 70 & 70 & 58 \\
\hline Mean & 790 & 91 & 68 & 65 & 52 \\
\hline \multicolumn{6}{|l|}{ PRPH } \\
\hline 1 & 580 & 91 & 89 & 84 & 76 \\
\hline $2^{a}$ & 1100 & 91 & 72 & 69 & 64 \\
\hline $3^{a}$ & 1680 & 92 & 81 & 73 & 40 \\
\hline $4^{a}$ & $2000^{b}$ & - & - & - & - \\
\hline Mean & 1340 & 91 & 81 & 75 & 60 \\
\hline
\end{tabular}

$\overline{\mathrm{H}^{+} \mathrm{A}^{+}=\text {monkeys with conjoint lesions of the hippocampus and the amygdala that }}$ included damage to the surrounding cortical regions, i.e., the perirhinal cortex, the entorhinal cortex, and the parahippocampal gyrus; PRPH = monkeys with conjoint lesions of the perirhinal cortex and the parahippocampal gyrus.

"Monkeys requiring a double sample presentation procedure (see text).

b Training was discontinued without the animal reaching a learning criterion.

contrast, the average scores for the $\mathrm{H}^{+} \mathrm{A}^{+}$monkeys using single sample presentations were 91,68 , and $65 \%$. Indeed, when the single-presentation procedure was used, the average scores across the 3 delays for the 2 PRPH monkeys (57\% and 67\%), were lower than any of those of the $4 \mathrm{H}^{+} \mathrm{A}^{+}$monkeys (range $=71 \%$ to $77 \%$ ).

Pattern discrimination. The numbers of trials required to learn the 2 pattern-discrimination problems were averaged together for each monkey (Fig. 7; monkey N4 performed continually at chance level on both problems, and testing on each problem was discontinued after 1000 trials. Monkey N6 performed continually at chance level on the first problem, and testing was discontinued after 1000 trials. On the second problem, N6 obtained a score of 720 trials; N6's score in Fig. 7 is 860 trials, the mean of the scores obtained on the 2 problems). There were no differences between any of the groups in terms of the number of trials required to learn $(p>0.10)$. Of the monkeys in the PRPH group, monkey PRPH4 required the most trials to learn the pattern discriminations.

Although the $\mathrm{H}^{+} \mathrm{A}^{+}$monkeys performed well on pattern discrimination, they performed poorly on the first few trials of each testing day, as reported previously (Zola-Morgan and Squire,

Figure 4. Photomicrographs of representative sections through the left and right temporal lobe of animal PRPH3. The sections are arranged from rostral $(A)$ to caudal $(H)$, and the lesion is indicated by arrowheads at each level. The asterisk on the right side of $A$ and $B$ indicates damage done during removal of the brain for histology and is not part of the lesion. The open arrow on the left side of $C$ indicates the site of retrograde tracer injection in the amygdala. Additional abbreviations: $A$, amygdala; $c s$, calcarine sulcus; $H$, hippocampal formation; or, optic radiations; $O A, T E$, $T E O$, fields of the occipital and inferotemporal cortex after Bonin and Bailey (1947); sts, superior temporal sulcus; $V$, ventricle. Scale bar, 3 mm. 

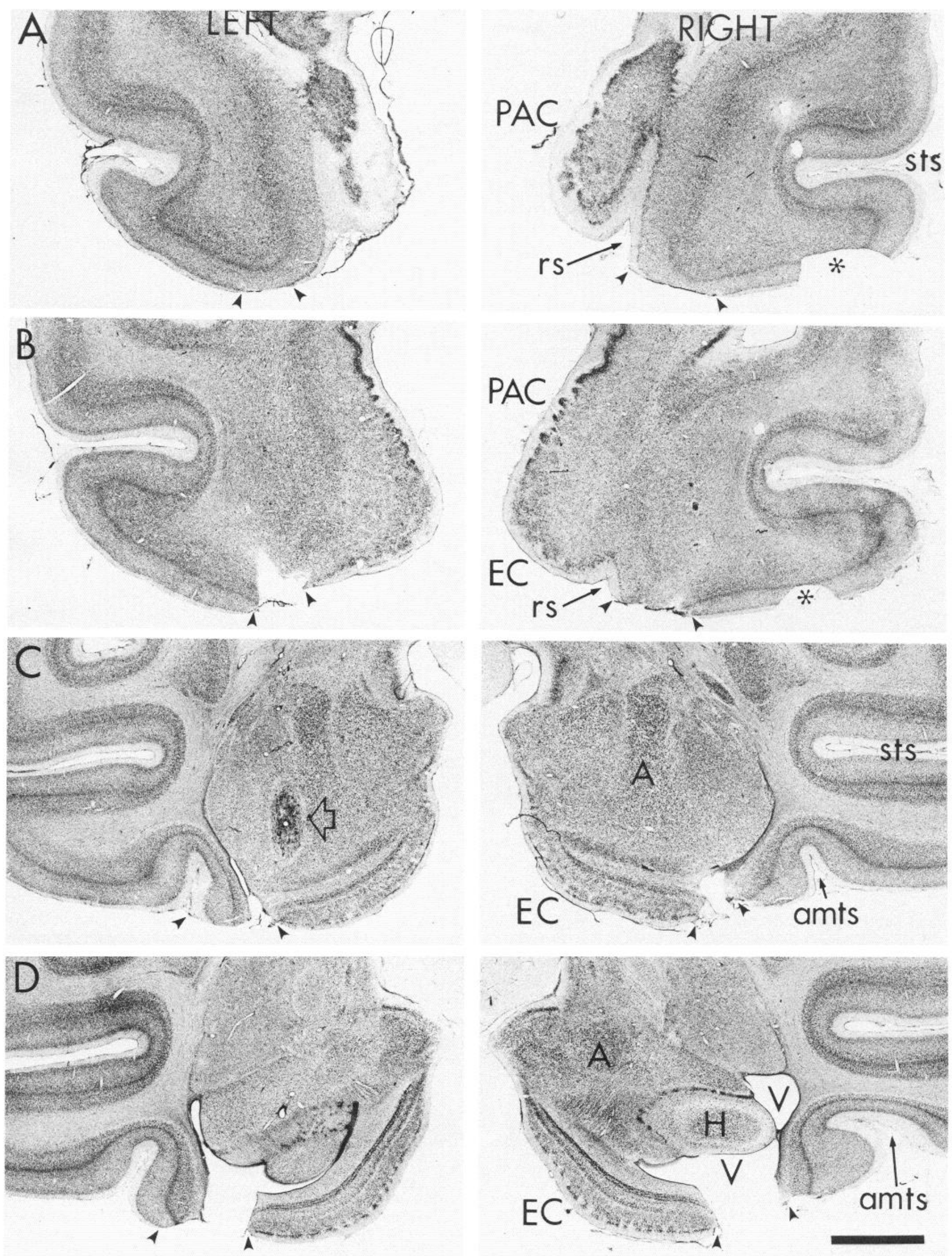

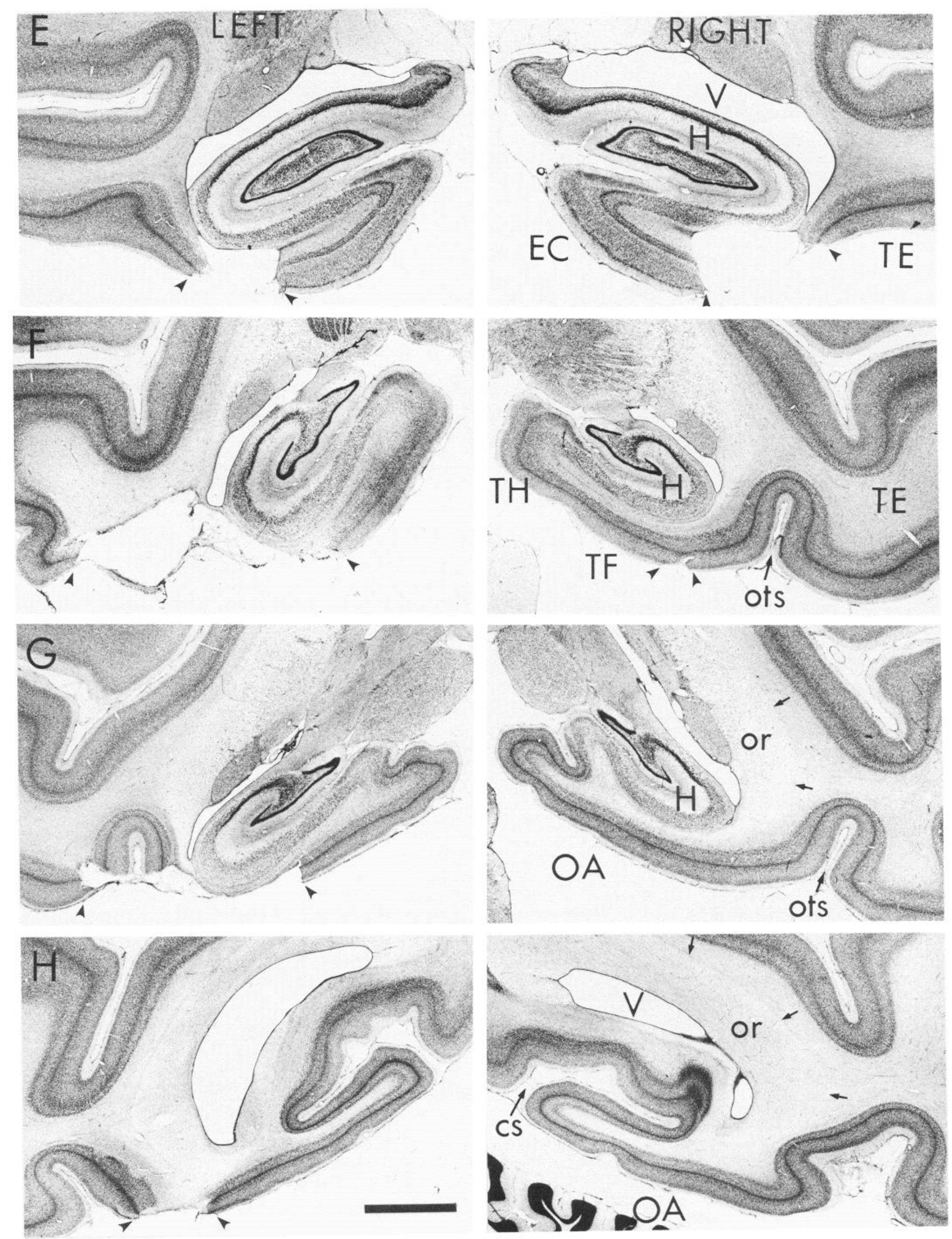

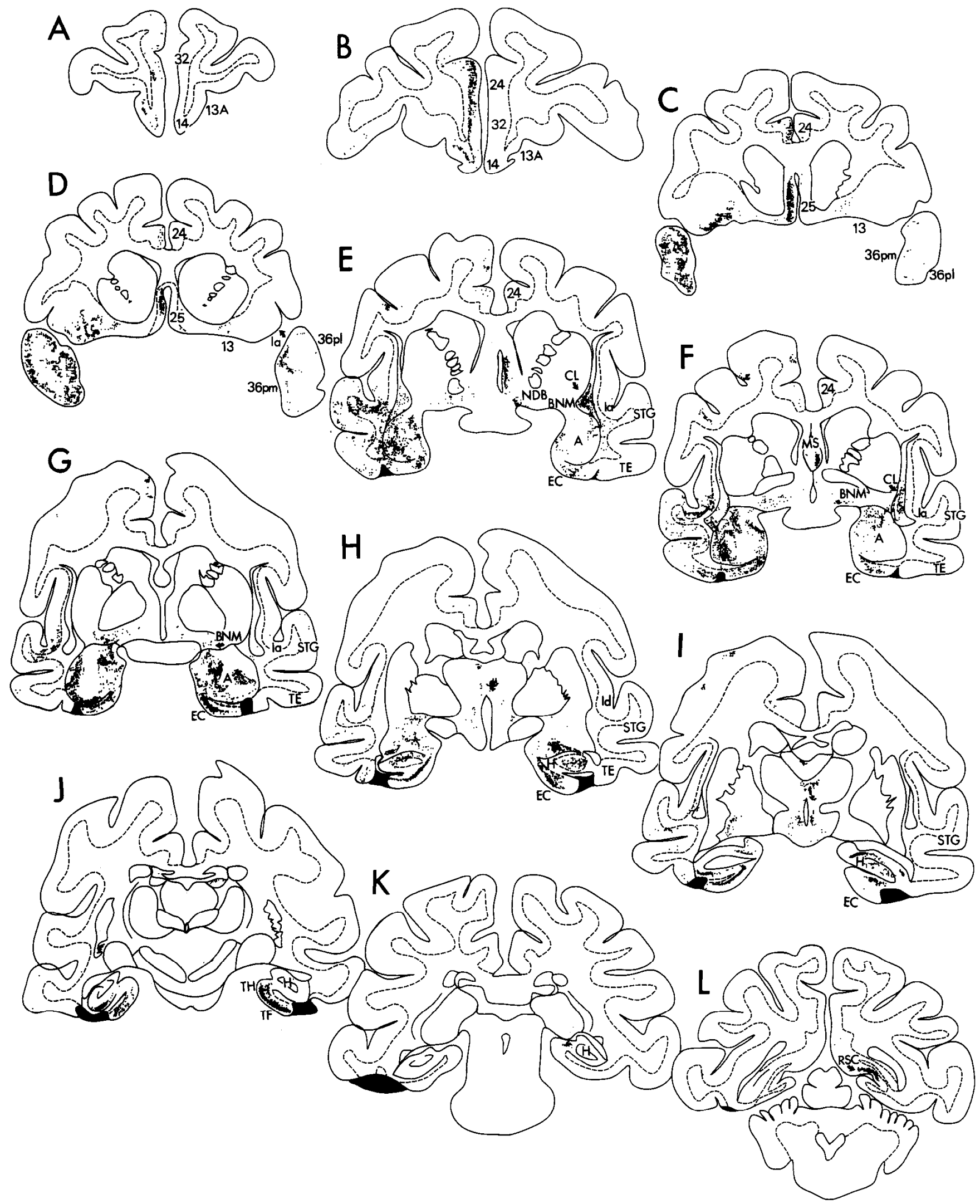

Figure 5. Computer plots of the distribution of retrogradely labeled cells in sections from animal PRPH 3 arranged from rostral $(A)$ to caudal $(L)$. Cells labeled from the injection of the amygdaloid complex are shown on the left side of each coronal section and those labeled from the entorhinal cortex injection are shown on the right. Each dot represents one labeled cell. The location of the lesion is indicated in black. Identification of the cortical fields follows the nomenclature of Bonin and Bailey (1947) or Brodmann (1909). 

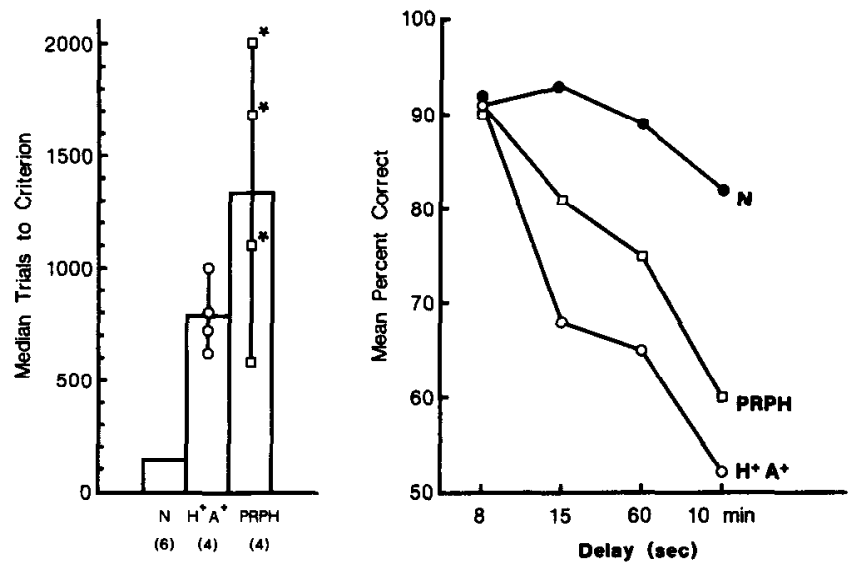

Figure 6. Performance on the delayed nonmatching to sample task by normal monkeys $(N)$, monkeys with conjoint lesions of the hippocampus and the amygdala that also damaged the surrounding cortical regions $\left(\mathrm{H}^{+} \mathrm{A}^{+}\right.$; Zola-Morgan and Squire, 1985), and monkeys with conjoint lesions of the perirhinal cortex and the parahippocampal gyrus $(P R P H)$. $A$, Initial learning of the task with a delay of $8 \mathrm{sec}$. Symbols show trials to criterion for individual animals (see Table 1). Asterisks indicate double sample presentation procedure. $B$, Performance across delays for the same groups. The curve for the PRPH group consists of data from 3 monkeys: monkey PRPH 1 using the single sample presentation procedure, and monkeys PRPH2 and PRPH3 using double sample presentation procedure. Monkey PRPH4 was not tested on delays (see Results for details).

1984). The PRPH group scored 54\% correct during the first 5 trials of all the daily test sessions [ $\mathrm{N}=79 \%$ correct (data from monkey N4 were not used in this analysis, and only the second problem was used for monkey $\mathrm{N} 6$ ), $\mathrm{H}^{+} \mathrm{A}^{+}=70 \%$ correct]. Both monkeys with PRPH lesions and monkeys with $\mathrm{H}^{+} \mathrm{A}^{+}$lesions were impaired $\left(\mathrm{N}_{\text {vs }} \mathrm{H}^{+} \mathrm{A}^{+}: t[7]=2.4, p<0.05\right.$; $\mathrm{N}$ vs PRPH: $t[7]=7.9, p<0.001)$. During the remaining trials of each test day, the 3 groups performed similarly $(\mathrm{N}=69 \%, \mathrm{PRPH}=63 \%$, $\mathrm{H}^{+} \mathrm{A}^{+}=67 \%$ ). In summary, the $\mathrm{H}^{+} \mathrm{A}^{+}$and the PRPH groups performed normally overall on the 2 pattern-discrimination tasks, but they were impaired on the first 5 trials of each test day. These findings support the suggestion that performance at the beginning of each test day during pattern-discrimination learning depends on a kind of memory that is sensitive to amnesia (Zola-Morgan and Squire, 1984).

Delayed retention of object discriminations. The data for all 4 discriminations were averaged together, and the mean percent correct score was calculated for each day of testing (Fig. 8). A 2-way analysis of variance involving all 3 groups revealed an overall group effect $(F[2,11]=35.1, p<0.001)$, an effect across days $(F[2,22]=26.9, p<0.001)$, and no group $\times$ day interaction $(F[4,22]=1.4)$. Separate comparisons between groups, with scores averaged across the three days (Table 2), showed that both operated groups were impaired ( $\mathrm{N}$ vs $\mathrm{H}^{+} \mathrm{A}^{+}: t[8]=$ $14.1, p<0.001 ; \mathrm{N}$ vs PRPH: $t[8]=5.8, p<0.01$ ). The 2 operated groups performed similarly overall $(p>0.10)$. Monkey PRPH4, which could not learn delayed nonmatching to sample, also obtained a lower overall performance score ( $68 \%$ correct) than any other monkey on the object discrimination tasks. Nevertheless, this monkey's overall performance score across the 4 object tasks was significantly above chance $(t=2.9, p<$ $0.05)$.

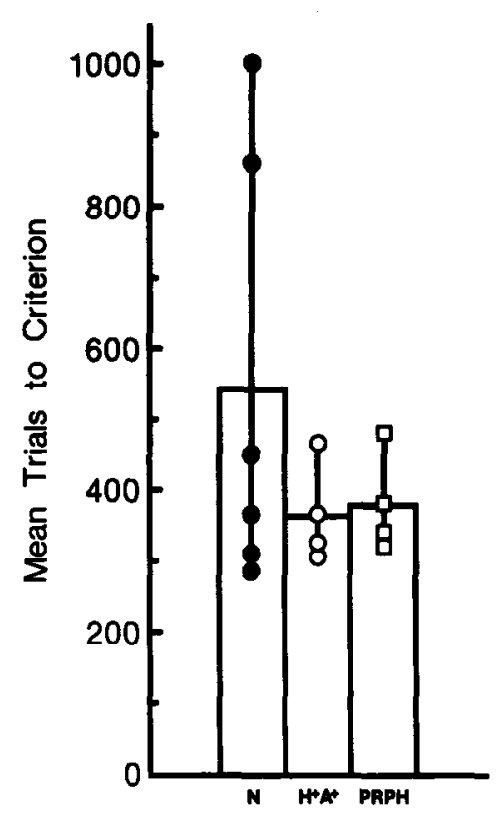

Figure 7. Average score on 2 pattern-discrimination tasks by normal monkeys $(N)$, monkeys with conjoint lesions of the hippocampus and the amygdala that also damaged the surrounding cortical regions, i.e., the perirhinal cortex, the entorhinal cortex, and the parahippocampal gyrus $\left(\mathrm{H}^{+} \mathrm{A}^{+}\right.$; Zola-Morgan and Squire, 1985), and monkeys with conjoint lesions of the perirhinal cortex and the parahippocampal gyrus $(P R P H)$. Symbols show scores for individual monkeys.

Concurrent discrimination. Scores for each group are presented in Figure 9. Individual scores appear in Table 2. Only 2 of the 4 monkeys in the PRPH group were tested. Neither of these monkeys learned the task within 1200 trials, and testing was discontinued at that point (average percent correct during the final 2 sessions: PRPH3 $=72 \%$, PRPH $4=53 \%$ ). Both the $\mathrm{H}^{+} \mathrm{A}^{+}$and the PRPH groups were impaired ( $p$ 's $<0.01$ ).

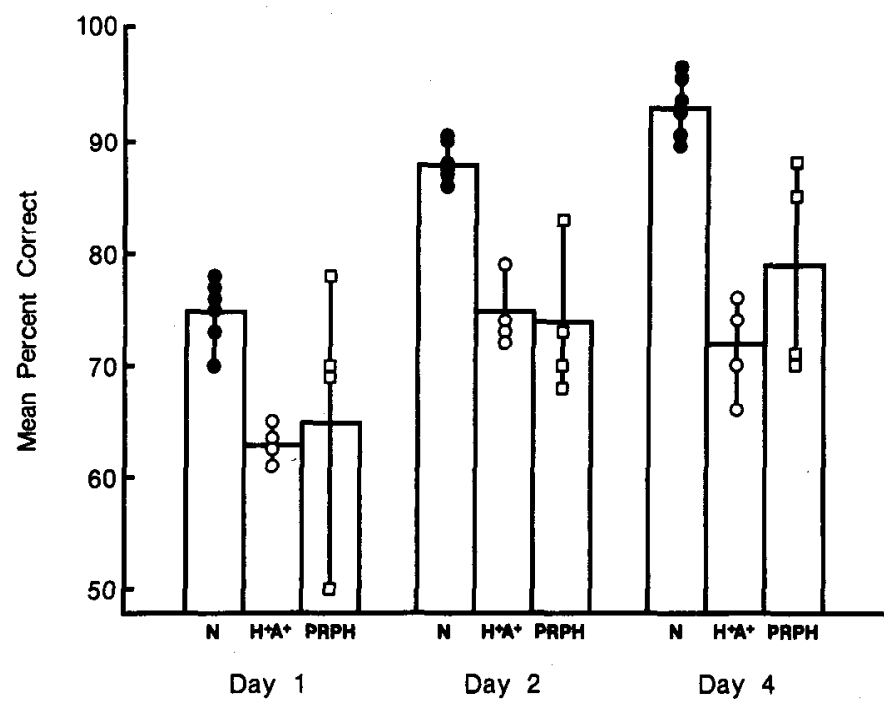

Figure 8 . Average daily performance on 4 object-discrimination tasks by normal monkeys $(N)$, monkeys with conjoint lesions of the hippocampus and the amygdala that also damaged the surrounding cortical regions, i.e., the perirhinal cortex, the entorhinal cortex, and the parahippocampal gyrus $\left(\mathrm{H}^{+} \mathrm{A}^{+}\right.$; Zola-Morgan and Squire, 1985), and monkeys with conjoint lesions of the perirhinal cortex and the parahippocampal gyrus $(P R P H)$. Symbols show scores for individual monkeys. 


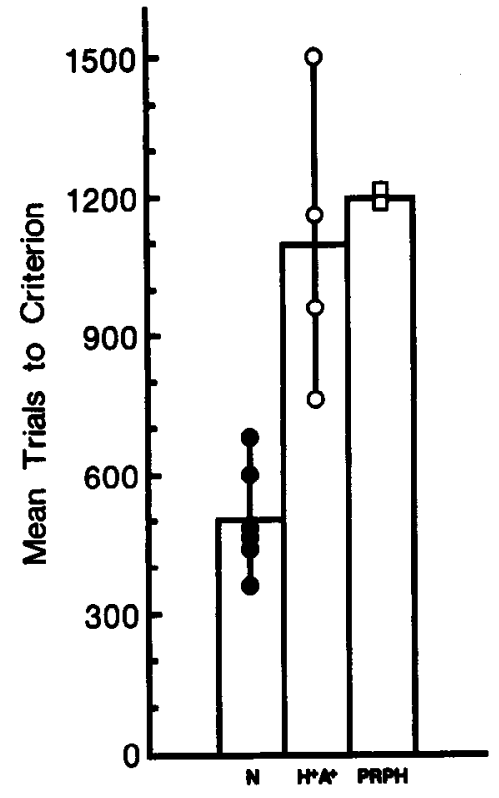

Figure 9. Performance on the 8-pair concurrent task by normal monkeys $(N)$, monkeys with conjoint lesions of the hippocampus and the amygdala that also damaged the surrounding cortical regions, i.e., the perirhinal cortex, the entorhinal cortex, and the parahippocampal gyrus $\left(\mathrm{H}^{+} \mathrm{A}^{+}\right.$; Zola-Morgan and Squire, 1985), and monkeys with conjoint lesions of the perirhinal cortex and the parahippocampal gyrus ( $P R P H)$. Symbols show scores for individual monkeys. Only 2 monkeys in the PRPH group were tested on this task, and testing was discontinued for these two monkeys at 1200 trials (average performance of the 2 monkeys for the last 100 trials $=63 \%$ correct).

\section{Discussion}

Monkeys with bilateral conjoint lesions of the perirhinal cortex and parahippocampal gyrus were severely impaired on 3 amnesia-sensitive tasks: delayed nonmatching to sample, delayed retention of object discriminations, and concurrent discrimination. On pattern discrimination, a task analogous to ones that amnesic patients perform well, monkeys in the PRPH group performed normally. The lesions in the 4 animals were quite similar, but animal PRPH1, who had the least severe memory impairment, also had a substantially smaller lesion than the other animals. Animal PRPH4, which had the most severe memory impairment, had the largest lesion of the group. Overall, the monkeys with PRPH lesions were as impaired or more impaired than the comparison group of monkeys with $\mathrm{H}^{+} \mathrm{A}^{+}$ lesions (Tables 1,2 ).

Performance on the delayed nonmatching to sample task clearly illustrates the severity of memory impairment in the PRPH group. Three of the 4 PRPH animals needed more trials than the $\mathrm{H}^{+} \mathrm{A}^{+}$animals to learn the basic task. Two of these animals (PRPH2 and PRPH3) were able to learn the task only when it was made easier by providing 2 presentations of the sample object on each trial, instead of one; despite the advantage provided by this procedure, these animals were as impaired across the delays as the $\mathrm{H}^{+} \mathrm{A}^{+}$animals. The third PRPH animal (PRPH4) was unable to learn the task despite receiving 1000 trials of double sample presentation and was not tested on the delays. The fourth PRPH animal (PRPH1) was only moderately impaired, and histological analysis indicated that the lesion in this animal was much smaller than the lesions of the other PRPH animals. Thus, while the scores are not directly comparable, the

\begin{tabular}{cccc}
\hline \multicolumn{4}{l}{ Table 2. Performance on tasks sensitive to amnesia } \\
\multicolumn{1}{c}{$\begin{array}{l}\text { Delayed } \\
\text { nonmatching }\end{array}$} & $\begin{array}{l}\text { Object } \\
\text { retention }\end{array}$ & $\begin{array}{c}\text { Concurrent } \\
\text { discrimination }\end{array}$ \\
\hline Normal & & & \\
1 & 90 & 83 & 440 \\
2 & 89 & 87 & 480 \\
3 & 81 & 84 & 680 \\
4 & 87 & 85 & 360 \\
5 & 91 & 86 & 480 \\
6 & 91 & 87 & 600 \\
Mean & 88 & 85 & 507 \\
$H^{+} A^{+}$ & & & \\
1 & 62 & 71 & 980 \\
2 & 59 & 69 & 1160 \\
3 & 58 & 71 & 760 \\
4 & 66 & 67 & 1520 \\
Mean & 61 & 70 & 1100 \\
PRPH & & & \\
1 & 83 & 80 & - \\
2 & $68^{a}$ & 73 & $1200^{b}$ \\
3 & $65^{a}$ & 71 & - \\
4 & - & 68 & 1200 \\
Mean & 72 & 73 & \\
\hline
\end{tabular}

The score for the Delayed Nonmatching task is the percent correct score averaged across 3 delays $(15 \mathrm{sec}, 60 \mathrm{sec}$, and $10 \mathrm{~min}$ ). The score for the Object Retention task is the percent correct score averaged across 3 test days. The score for Concurrent Discrimination is the number of trials required to reach the learning criterion. $\mathrm{H}^{+} \mathrm{A}^{+}=$monkeys with conjoint lesions of the hippocampus and the amygdala that included damage to the surrounding cortical regions; PRPH = monkeys with conjoint lesions of the perirhinal cortex and the parahippocampal gyrus.

${ }^{a}$ Monkeys requiring a double sample presentation procedure (see text).

"Training was discontinued without the animal reaching the learning criterion.

PRPH animals as a group performed more poorly on the delayed nonmatching to sample task than the $\mathrm{H}^{+} \mathrm{A}^{+}$animals.

The severe memory impairment following PRPH lesions can be understood in terms of the anatomical connections between the damaged areas and the hippocampal formation. Specifically, perirhinal cortex and parahippocampal cortex provide nearly two-thirds of the cortical input to the entorhinal cortex (Insausti et al., 1987) and are therefore essential for the normal exchange of information between the neocortex and the hippocampal formation. In addition, because we damaged projections to entorhinal cortex that originate in cortical regions other than the perirhinal and parahippocampal cortices, damage to these projections may also have contributed to the severity of the deficit that was observed. Importantly, because the PRPH lesion produced more severe impairment than a lesion limited to the hippocampal formation and the parahippocampal cortex, the $\mathrm{H}^{+}$lesion (Zola-Morgan and Squire, 1986; Zola-Morgan et al., 1989a), and because the perirhinal cortex is the only component of the PRPH lesion that is not included in the $\mathrm{H}^{+}$lesion, the more severe impairment associated with the PRPH lesion indicates that the perirhinal cortex itself must contribute significantly to memory functions. Thus, the PRPH lesion does not simply disconnect areas significant for memory. Rather, the perirhinal and parahippocampal cortices, and possibly other cortical areas whose projections to entorhinal cortex were damaged by the lesion, must normally contribute to memory functions. 
The finding of severe memory impairment following PRPH lesions is consistent with reports that cooling the parahippocampal gyrus in monkeys impairs performance on the delayed matching to sample task (George et al., 1989). In addition, performance was impaired after cooling the anteroventral temporal cortex (Horel and Pytko, 1982), which seems likely to have involved perirhinal cortex in addition to area TE.

The possibility must be considered that the PRPH lesions not only disrupted the normal function of the hippocampal formation but also adversely affected the function of the amygdaloid complex. By this view, the impairment produced by the PRPH lesion might be considered to have resulted from its combined indirect effects on hippocampus and amygdala function, just as the $\mathrm{H}^{+} \mathrm{A}^{+}$lesion has been considered to depend on conjoint, direct damage to the hippocampus and amygdala (Mishkin, 1978; Murray and Mishkin, 1984, 1986; Saunders et al., 1984; Bachevalier et al., 1985).

This possibility seems unlikely for 3 reasons. First, the perirhinal and parahippocampal cortices provide relatively little of the cortical input to the amygdaloid complex (Aggleton et al., 1980). Moreover, the majority of the perirhinal projection to the amygdaloid complex arises from the temporal polar portion of the perirhinal cortex (Aggleton et al., 1980; Van Hoesen et al., 1981; D. G. Amaral and R. Insausti, unpublished observations). Much of this region was spared in the 4 monkeys with PRPH lesions.

Second, retrogradely labeled injections of tracers into the entorhinal cortex or the amygdaloid complex in 2 of the PRPH animals showed that cortical afferents to the entorhinal cortex were massively depleted by the PRPH lesion, whereas the density and distribution of cortical projections to the amygdaloid complex appeared fairly normal. Third, unlike monkeys with amygdala lesions, who exhibited reduced fearfulness and exaggerated investigatory behavior on formal tests of reactivity to objects, all the monkeys with PRPH lesions were normal on the same tests (Alvarez-Royo et al., 1988). While these findings indicate that the PRPH lesion did not significantly disrupt amygdala function, it is difficult to rule out completely the possibility that the PRPH lesion disrupted projections to the amygdala that are critical for memory function but not for emotional behavior. Still, this possibility does seem unlikely, in view of our previous findings that large, selective lesions of the amygdala did not cause significant memory impairment or exacerbate the memory impairment associated with damage to the hippocampal formation (Zola-Morgan et al., 1989b). That is, if total removal of the amygdala did not contribute to memory impairment, it seems unlikely that the severe memory impairment produced by PRPH lesions can be attributed to the minor amygdaloid deafferentation that may have been associated with perirhinal cortex damage.

Our inference that damage to perirhinal cortex and hippocampal formation, and not damage to the amygdala, contributes to impaired performance on delayed nonmatching to sample and other amnesia-sensitive tasks differs from the conclusion reached in a series of other studies involving $\mathrm{H}^{+} \mathrm{A}^{+}$lesions, $\mathrm{A}^{+}$ lesions, or damage to the amygdalofugal pathway (Mishkin, 1978; Saunders et al., 1984; Bachevalier et al., 1985; Murray and Mishkin, 1986). Although none of these studies included coronal sections anterior enough to evaluate fully the status of perirhinal cortex, significant perirhinal damage can occur during the surgical approach to the amygdala that was used in the studies (see the histological findings in Results).
More recently, severe memory impairment was reported following combined damage to the amygdala and rhinal cortex (i.e., all of entorhinal cortex plus a portion of perirhinal cortex). Less severe impairment was observed following combined damage to the hippocampus and rhinal cortex (Murray and Mishkin, 1986). (The parahippocampal gyrus was also damaged in the second group.) It is likely that more perirhinal damage occurred in the amygdala plus rhinal group than in the hippocampus plus rhinal group. First, perirhinal damage in the amygdala plus rhinal group extended at least to level A. +20 , the most anterior level illustrated. In the hippocampal plus rhinal group, perirhinal damage is shown extending only to level A. +17 (figures 2 and 6, Murray and Mishkin, 1986). Second, the anterior portion of perirhinal cortex is often damaged during the frontal surgical approach used in the amygdala plus rhinal group, but not in the ventral temporal approach used for the hippocampus plus rhinal group. It would be useful to reexamine the extent of perirhinal damage in these experimental groups, with special attention to the extent of anterior perirhinal damage (see Fig. 1).

In summary, the present findings, together with recent neuroanatomic evidence that the perirhinal cortex and parahippocampal gyrus comprise a major afferent and efferent system of the hippocampal formation, emphasize the importance for memory functions of the hippocampal formation and the surrounding cortex of the medial temporal lobe (also see Van Hoesen and Damasio, 1987; Friedman and Goldman-Rakic, 1988). Specifically, the findings suggest that the severe memory impairment in monkeys and humans associated with bilateral medial temporal lobe lesions may result from damage to hippocampal formation and adjacent, anatomically related cortex, not from conjoint hippocampus-amygdala damage. Importantly, the present finding of severe memory impairment following PRPH lesions and the finding of less impairment following $\mathrm{H}^{+}$lesions (Zola-Morgan and Squire, 1986; Zola-Morgan et al., 1989a) suggest that the perirhinal cortex itself, in addition to the hippocampal formation, must contribute significantly to memory function. Finally, these findings are not inconsistent with the idea that the amygdala plays an important role in cognitive functions, including certain kinds of memory functions (Mishkin and Aggleton, 1981; Murray and Mishkin, 1985; Gaffan and Harrison, 1987). However, where these ideas derive from lesion studies, the contribution of overlying cortical regions included in the amygdala lesion will need to be reevaluated.

\section{References}

Aggleton, J. P., and M. Mishkin (1983) Visual recognition impairment following medial thalamic lesions in monkeys. Neuropsychologia 21 : 187-197.

Aggleton, J. P., M. J. Burton, and R. E. Passingham (1980) Cortical and subcortical afferents to the amygdala of the rhesus monkey. Brain Res. 190: 347-368.

Alvarez-Royo, P., M. Mesches, J. Allen, W. Saltzmann, L. R. Squire, and $S$. Zola-Morgan (1988) Independence of memory functions and emotional behavior: Separate contributions of the hippocampal formation and the amygdala. Soc. Neurosci. Abstr. 14: 1194.

Amaral, D. G., R. Insausti, and W. M. Cowan (1987) The monkey entorhinal cortex. I. Cytoarchitectonic organization. J. Comp. Neurol. 264: $326-355$

Bachevalier, J., J. K. Parkinson, and M. Mishkin (1985) Visual recognition in monkeys: Effects of separate versus combined transection of fornix and amydalofugal pathways. Exp. Brain Res. 57: 554-561.

Bonin, G., and P. Bailey (1947) The Neocortex of Macaca mulatta, University of Illinois Press, Urbana, IL.

Brodmann, K. (1909) Vergleichende Lokalisationslehre der Grosshirnrinde, Barth, Leipzig. 
Friedman, H. R., and P. S. Goldman-Rakic (1988) Activation of the hippocampus and dentate gyrus by working-memory: A 2-deoxyglucose study of behaving rhesus monkeys. J. Neurosci. 8: 4693-4706.

Gaffan, D., and S. Harrison (1987) Amygdalectomy and disconnection in visual learning for auditory secondary reinforcement by monkeys. J. Neurosci. 7: 2285-2292.

George, P. J., J. A. Horel, and R. A. Cirillo (1989) Reversible cold lesions of the parahippocampal gyrus in monkeys result in deficits on the delayed match-to-sample and other visual tasks. Behav. Brain Res. (in press).

Harlow, H., and J. A. Bromer (1938) A test-apparatus for monkeys. Psychol. Rev. 19: 434-438.

Hartley, L. H., R. Roger, R. J. Nicolosi, and T. Hartley (1984) Blood pressure values in Macaca fascicularis. J. Med. Primatol. 13: 183189.

Horel, J. A., and D. E. Pytko (1982) Behavioral effects of local cooling in temporal lobe of monkeys. J. Neurophysiol. 47: 11-22.

Insausti, R., D. G. Amaral, and W. M. Cowan (1987) The entorhinal cortex of the monkey: II. Cortical afferents. J. Comp. Neurol. 264: 356-395.

Mahut, H., and M. Moss (1984) Consolidation of memory: The hippocampus revisited. In Neuropsychology of Memory, L. R. Squire and N. Butters, eds., Guilford, New York.

Mahut, H., S. Zola-Morgan, and M. Moss (1982) Hippocampal resections impair associative learning and recognition memory in the monkey. J. Neurosci. 1: 227-240.

Mehler, W. R. (1980) Subcortical afferent connections of the amygdala in the monkey. J. Comp. Neurol. 190: 733-762.

Mishkin, M. (1978) Memory in monkeys severely impaired by combined but not separate removal of the amygdala and hippocampus. Nature 273: 297-298.

Mishkin, M. (1982) A memory system in the monkey. Phil. Trans. R. Soc. London [Biol.] 298: 85-89.

Mishkin, M., and J. P. Aggleton (1981) Multiple functional contributions of the amygdala in the monkey. In The Amygdaloid Complex, Y. Ben-Ari, ed., pp. 409-422, Elsevier/North Holland, Amsterdam.

Murray, E. A., and M. Mishkin (1984) Severe tactual as well as visual memory deficits follow combined removal of the amygdala and hippocampus in monkeys. J. Neurosci. 4: 2565-2580.

Murray, E. A., and M. Mishkin (1985) Amygdalectomy impairs crossmodal association in monkeys. Science 228: 604-605.

Murray, E. A, and M. Mishkin (1986) Visual recognition in monkeys following rhinal cortical ablations combined with either amygdalectomy or hippocampectomy. J. Neurosci. 6: 1991-2003.

Norita, M., and K. Kawamura (1980) Subcortical afferents to the monkey amygdala: An HRP study. Brain Res. 190: 225-230.
Saunders, R. C., E. A. Murray, and M. Mishkin (1984) Further evidence that amygdala and hippocampus contribute equally to recognition memory. Neuropsychologia 22: 785-796.

Scoville, W. B., and B. Milner (1957) Loss of recent memory after bilateral hippocampal lesions. J. Neurol. Neurosurg. Psychiatry 20: 11-21.

Squire, L. R., and S. Zola-Morgan (1983) The neurology of memory: The case for correspondence between the findings for man and nonhuman primate. In The Physiological Basis of Memory, 2nd ed, J. A. Deutsch, ed., pp. 199-268, Academic, New York.

Squire, L. R., S. Zola-Morgan, and K. S. Chen (1988) Human amnesia and animal models of amnesia: Performance of amnesic patients on tests designed for the monkey. Behav. Neurosci. 102: 210-221.

Szabo, J., and W. M. Cowan (1984) A stereotaxic atlas of the brain of the cynomolgus monkey (Macaca fascicularis). J. Comp. Neurol. 222: 265-300.

Van Hoesen, G. W., and A. R. Damasio (1987) Neural correlates of cognitive impairment in Alzheimer's disease. In Handbook of Physiology, Section 1: The Nervous System; Vol. 5. Higher Functions of the Brain, F. Plum, ed., American Physiological Society, Bethesda, MD.

Van Hoesen, G. W., E. H. Yeterian, and R. Lavizzo-Mourey (1981) Widespread corticostriate projections from temporal cortex of the rhesus monkey. J. Comp. Neurol. 199: 205-219.

Zola-Morgan, S., and L. R. Squire (1984) Preserved learning in monkeys with medial temporal lesions: Sparing of cognitive skills. J. Neurosci. 4: 1072-1085.

Zola-Morgan, S., and L. R. Squire (1985) Medial temporal lesions in monkeys impair memory in a variety of tasks sensitive to human amnesia. Behav. Neurosci. 99: 22-34.

Zola-Morgan, S., and L. R. Squire (1986) Memory impairment in monkeys following lesions of the hippocampus. Behav. Neurosci. 100: 165-170.

Zola-Morgan, S., L. R. Squire, and M. Mishkin (1982) The neuroanatomy of amnesia: The amygdala-hippocampus vs. temporal stem. Science 218: 1337-1339.

Zola-Morgan, S., L. R. Squire, and D. G. Amaral (1989a) Lesions of the hippocampal formation but not lesions of the fornix or the mammillary nuclei produce long-lasting memory impairment in monkeys. J. Neurosci. 9: 897-912.

Zola-Morgan, S., L. R. Squire, and D. G. Amaral (1989b) Lesions of the amygdala that spare adjacent cortical regions do not impair memory or exacerbate the impairment following lesions of the hippocampal formation. J. Neurosci. 9: 1922-1936. 